\title{
Power quality improvement with a shunt active power filters using MATLAB / Simulink
}

\author{
D.SANDEEP KUMAR ${ }^{1}$, G.VENU MADHAV ${ }^{2}$
}

M.TECH (EPS), Padmasri Dr. B. V. Raju Institute of Technology, Narsapur, Medak Dist,Telangana, India ${ }^{1}$

M.TECH(PH.D) LMISTE, Associate professor department of EEE, Padmasri Dr. B. V. Raju Institute of Technology,

\author{
Narsapur, Medak Dist,Telangana, India ${ }^{2}$
}

\begin{abstract}
Along with the increasing demand on improving power quality i.e generally defined as any change in power (voltage, current, or frequency) that interferes with the normal operation of electrical equipment, the most popular technique that has been used is Active Power Filter (APF); This is because Passive filters performance is limited to a few harmonics and they can introduce resonance in the power system. Passive filters are larger component sizes and therefore Costs high. So APF can easily eliminate unwanted harmonics, improve power factor and overcome voltage sags and eliminate any harmonic frequencies. This paper will discuss and analyze the simulation result for a three-phase three wire shunt active power filter using MATLAB program. This simulation will implement a non-linear load, to compensate line current harmonics under balanced and unbalance loads. As a result of the simulation, it is found that an active power filter is the better way to reduce the total harmonic distortion (THD)
\end{abstract}

Keywords: APF, PWM converter, d-q theorm, THD, Power Quality, Instantaneous Power theory

\section{INTRODUCTION}

A harmonic is a component of a periodic wave having a For example, using a 6 pulse rectifier, the characteristic frequency that is an integral multiple of the fundamental harmonics will be: multiple of the fundamental frequency. Total harmonic $h=(2 \times 6) \pm 1$ distortion is the contribution of all the harmonic frequency $h=(3 \times 6) \pm 1$ 11th \&13th harmonics 17 th \&19th harmonics currents to the fundamental.

\section{HOW HARMONICS ARE PRODUCED}

Harmonics are the by-products of modern electronics. They occur frequently when there are large numbers of personal computers (single phase loads), uninterruptible power supplies (UPSs), variable frequency drives (AC and DC) or any electronic device using solid state power switching supplies to convert incoming AC to DC. Non-linear loads create harmonics by drawing current in abrupt short pulses, rather than in a smooth sinusoidal manner.
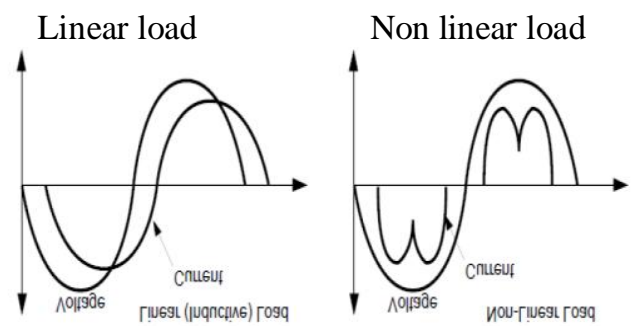

Harmonic is defined as "a sinusoidal component of a periodic wave or quantity having a frequency that is an integral multiple of the fundamental frequency". Harmonic is turn out of several of frequency current or voltage multiply by the fundamental voltage or current in the system. Previous technique used to compensate load current harmonics is L-C passive filter; as a result the filter cannot a dapt for various $r$ ange of load current a n d sometimes produce undesired resonance.

Efficiency and controllability is increasing the concern for harmonic distortion levels in end user facilities and on the overall power system". The harmonic standard was invigilated with the objective of this standard is to provide general harmonic evaluation procedures for different classes of customer such as industrial, commercial and residential. Illustrated methods for evaluating of harmonics control at the customer level and the utility system. Expert devices such as ovens that produce heat are commonly sensitive to harmonics. There are many problems caused by harmonics in the power system and electrical loads such as a Disturbance to Electrical and Electronics

The terms "linear" and "non-linear" define the relationship of current to the voltage waveform. A linear relationship exists between the voltage and current, which is typical of an across-the-line load. A non-linear load has a discontinuous current relationship that does not correspond to the applied voltage waveform.

$\mathrm{h}=(\mathrm{n} \times \mathrm{p}) \pm 1$ where: $\mathrm{n}=$ an integer $(1,2,3,4,5 \ldots)$

$\mathrm{p}=$ number of pulses or rectifiers Working of Metering Devices, De-Rating of Distribution.

\section{ACTIVE POWER FILTERS}

Active power filters are basically of two types i.e. shunt active power filter and series active power filters. Here we are mainly concentrate on the shunt active filters. 


\section{SHUNT ACTIVE FILTERS}

The concept of shunt active filtering was first introduced by Gyugyi and Strycula in 1976. Nowadays, a shunt active filter is not a dream but a reality, and many shunt active filters are in commercial operation all over the world. Their controllers determine in real time the compensating current reference, and force a power converter to synthesize it accurately. In this way, the active filtering can be selective and adaptive. In other words, a shunt active filter can compensate only for the harmonic current of a selected nonlinear load, and can continuously track changes in its harmonic content

The shunt active power filter, with a self-controlled dc bus, has a topology similar to that of a static compensator (STATCOM) used for reactive power compensation in power transmission systems. Shunt active power filters compensate load current harmonics by injecting equal but opposite harmonic compensating current. In this case the shunt active power filter operates as a current source injecting the harmonic components generated by the load but phase shifted by $180^{\circ}$

Active filter have been designed, improved, and commercialized in past three decades. They are applicable to compensate current-based distortions such as current harmonics, reactive power and neutral current. They are also used for voltage-based distortion such as voltage harmonics, voltage flickers, voltage sags and swells, voltage imbalances.

They are two categories of active filter such as singlephase and three-phase. Three-phase active filters may be with or without neutral connection and single phase active filters are used to compensate power quality problems caused by single-phase loads such as DC power supplies. Three-phase active filters are used for high power nonlinear loads such as adjustable speed drive (ASD) and Ac to DC converters.

Based on topologies, they are two kinds of active filte rsuch as current source and voltage source

active filters. Current source active filters (CSAF) employ an inductor as the DC energy storage device as shows in Fig. 1. In voltage source active filter (VSAF), a capacitor acts as the storage element .VSAF are inexpensive, lighter, and easier to control

compare to CSAF. There are types of connection that can be used for active filter such as shunt active filter, series active filter, parallel active filter.

Harmonic currents are generated mainly due to the presence of:

Nonlinear loads

Harmonic voltages in the power system

A nonlinear load draws a fundamental current component $\mathrm{I}_{\mathrm{LF}}$ and a harmonic current $\mathrm{I}_{\mathrm{Lh}}$ from the power system. The harmonic current $\mathrm{I}_{\mathrm{Sh}}$, is induced by the source harmonic voltage $\mathrm{V}_{\mathrm{Sh}}$. A shunt active filter can compensate both harmonic currents $I_{S h}$ and $I_{L h}$, however the principal function of a shunt active filter is compensation of the load harmonic current $\mathrm{I}_{\mathrm{Lh}}$, this means that the active filter confines the load harmonic current at the load terminals, hindering its penetration into the power system. For simplicity the power system is represented only by an equivalent impedance $\mathrm{X}_{\mathrm{L}}$ in Fig.4.1. If the load harmonic current $\mathrm{I}_{\mathrm{Lh}}$, flows through the power system, it produces an additional harmonic voltage drop equal to $\mathrm{V}_{\mathrm{T}}=\mathrm{X}_{\mathrm{L}} * \mathrm{I}_{\mathrm{Lh}}$, that further degenerates the load terminal voltage $\mathrm{V}_{\mathrm{T}}$.

The principle of shunt current compensation shown in Fig.4.1 is very effective in compensating harmonic currents of loads. However, a shunt active filter that realizes this principle of shunt current compensation should also draw an additional harmonic current in order to keep the load terminal voltage sinusoidal and equal to $\mathrm{V}_{\mathrm{T}}=$ $\mathrm{V}_{\mathrm{SF}}-\mathrm{X}_{\mathrm{L}} * \mathrm{I}_{\mathrm{LF}}$. The harmonic voltage drop appearing across the equivalent impedance becomes equal to the source harmonic voltage if $\mathrm{V}_{\mathrm{Sh}}=\mathrm{X}_{\mathrm{L}} * \mathrm{I}_{\mathrm{Sh}}$. In this case, the harmonic voltage components cancel each other, so that the terminal voltage $\mathrm{V}_{\mathrm{T}}$, is kept sinusoidal.

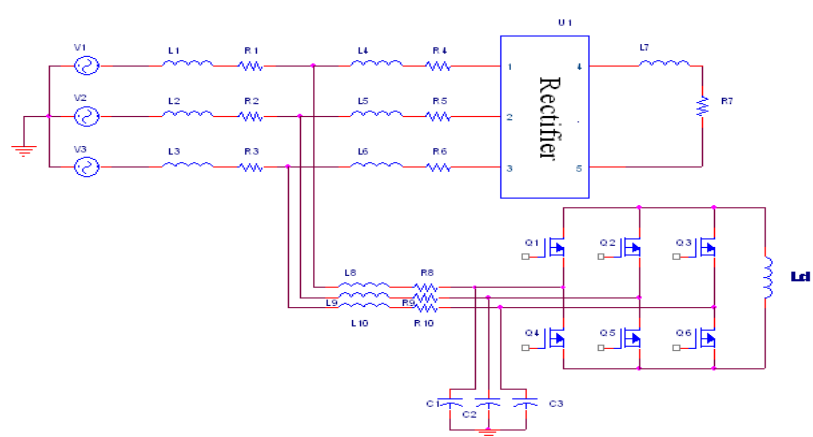

Fig. 1. A typical three-phase current source active filter (CSAF)

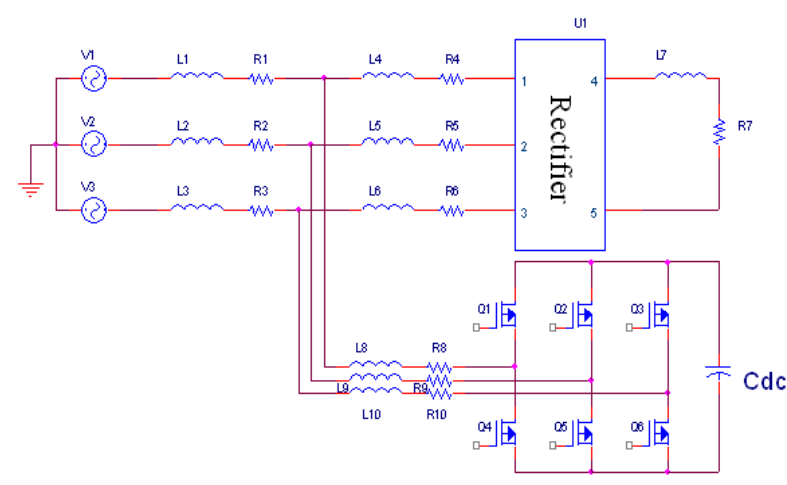

Fig.2 A typical three-phase voltage source(VSAF)

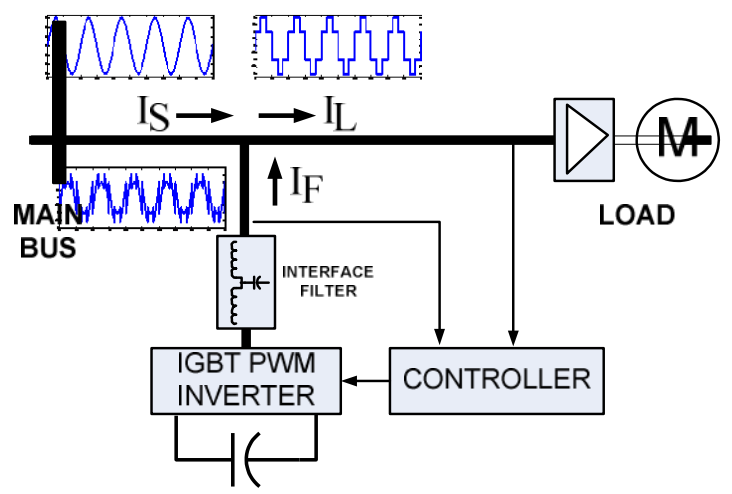


Fig.3. Diagram illustrating component of shunt connected active filter with the waveform show

\section{PROPOSED CONTROL STRATEGY}

\subsection{The p-q theory in Three-Phase, Three-Wire System} This concept is very popular and, basically consists of a variable transformation from $a, b, c$, reference frame of the instantaneous power, voltage, and current signals to the $\alpha, \beta$ reference frame. The transformation equations from the a, b, c, reference frame to the $\alpha, \beta, 0$ coordinates can be derived from the phasor diagram shown in Fig.3.1
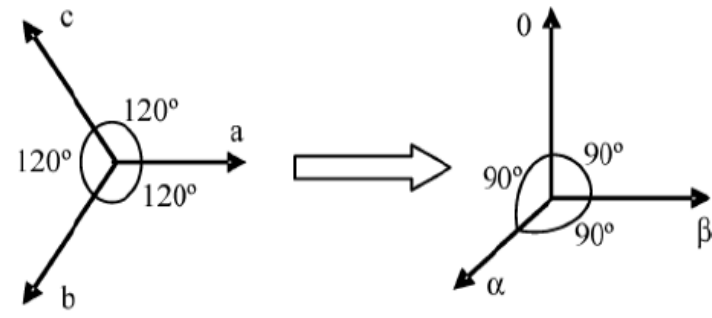

3.1 Transformation from the phase reference system(a, b, c) to $(\alpha, \beta, 0)$ system

The instantaneous values of voltages and currents in the $\alpha, \beta$ coordinates can be obtained from the following equations, the Clarke transformation and inverse Clarke transformation of three phase generic voltage given by, Similarly three phase generic instantaneous line currents ia, ib, ic can be transform on the $\alpha \beta$ axis by

This transformation is valid if and only if $\mathrm{V}_{\mathrm{a}}(\mathrm{t})+\mathrm{V}_{\mathrm{b}}(\mathrm{t})+$ $\mathrm{V}_{\mathrm{c}}(\mathrm{t})$ is equal to zero, and also if the voltages are balanced and sinusoidal. The instantaneous active and reactive power in the $\alpha \beta$ coordinates are calculated with the following expressions

The instantaneous complex power is possible using the instantaneous vectors of voltage and current. The instantaneous complex power is defined as the product of the voltage $\mathrm{V}$ and the conjugate of the current vector $\mathrm{i}^{*}$, given in the form of complex numbers

\subsection{INSTANTNEOUS POWER THEORY}

$\mathrm{S}=\mathrm{V}^{*} \mathrm{i}^{*}=\left(\mathrm{v}_{\alpha}+j \mathrm{v}_{\beta}\right) *\left(\mathrm{i}_{\alpha}-\mathrm{ji} \mathrm{i}_{\beta}\right)=\left(\mathrm{v}_{\alpha} \mathrm{i}_{\alpha}+\mathrm{v}_{\beta} \mathrm{i}_{\beta}\right)+\mathrm{j}\left(\mathrm{v}_{\beta} \mathrm{i}_{\alpha}-\mathrm{v}_{\alpha} \mathrm{i}_{\beta}\right)$

From this active and reactive power components are

$$
\begin{aligned}
& \mathrm{p}=\mathrm{v}_{\alpha} \dot{i}_{\alpha}+\mathrm{v}_{\beta} i_{\beta} \\
& \mathrm{q}=\mathrm{v}_{\alpha} \dot{i}_{\beta}-\mathrm{v}_{\beta} \dot{i}_{\alpha}
\end{aligned}
$$

For systems that do not have a neutral connection, the $\mathrm{z}$ ero sequence does not exist and the mathematical equation will be presented in matrix form

$$
\left[\begin{array}{l}
V_{\alpha} \\
V_{\beta}
\end{array}\right]=\sqrt{\frac{2}{3}}\left[\begin{array}{rrr}
1 & -\frac{1}{2} & -\frac{1}{2} \\
0 & \frac{\sqrt{3}}{2} & -\frac{\sqrt{3}}{2}
\end{array}\right]\left[\begin{array}{c}
V_{a} \\
V_{b} \\
V_{c}
\end{array}\right]
$$

And

$$
\left[\begin{array}{l}
i_{\alpha} \\
i_{\beta}
\end{array}\right]=\sqrt{\frac{2}{3}}\left[\begin{array}{ccc}
1 & -\frac{1}{2} & -\frac{1}{2} \\
0 & \frac{\sqrt{3}}{2} & -\frac{\sqrt{3}}{2}
\end{array}\right]\left[\begin{array}{l}
i_{a} \\
i_{b} \\
i_{c}
\end{array}\right]
$$

From this active and reactive components are

$$
\begin{aligned}
& \mathrm{p}=\mathrm{v}_{\alpha} i_{\alpha}+\mathrm{v}_{\beta} i_{\beta} \\
& \mathrm{q}=\mathrm{v}_{\alpha} i_{\beta}-\mathrm{v}_{\beta} i_{\alpha}
\end{aligned}
$$

The active and reactive powers in matrix form is given below

$$
\left[\begin{array}{l}
p \\
q
\end{array}\right]=\left[\begin{array}{cc}
V_{\alpha} & V_{\beta} \\
-V_{\beta} & V_{\alpha}
\end{array}\right]\left[\begin{array}{l}
i_{\alpha} \\
i_{\beta}
\end{array}\right]
$$

Active and reactive powers can be separated into two parts which are AC part and DC part as shown below

$$
\begin{aligned}
& \mathrm{p}=\bar{p}+\tilde{p} \\
& \mathrm{q}=\bar{q}+\tilde{q}
\end{aligned}
$$

In order to get the DC part of the active and reactive power, the signals need to be filtered using low pass filter. The low-pass filter will remove the high frequency component and give the fundamental part.

Where $\bar{p}$ is DC component of the instantaneous power $\mathrm{p}$ is related to the conventional fundamental active current.

$\tilde{p}$ is the ac component of the instantaneous power $\mathrm{p}$, it does not have average value, and is related to the harmonic currents caused by the ac component of the instantaneous real power $\bar{q}$ is the dc component of the imaginary instantaneous power q, and is related to the reactive power generated by the fundamental components of voltages and currents. $\widetilde{q}$ is the ac component of the instantaneous imaginary power $\mathrm{q}$, and it is related to the harmonic currents caused by the ac component of instantaneous reactive power.

In order to compensate reactive power and current harmonics generated by non-linear loads, the reference signal of the shunt active power filter must include the values of $\tilde{p}, \bar{q}$ and $\tilde{q}$. In this case the reference currents required by the shunt active power filters are calculated with the following expression:

$$
\left[\begin{array}{l}
i_{C \alpha}^{*} \\
i_{C \beta}^{*}
\end{array}\right]=\frac{1}{V_{\alpha}^{2}+V_{\beta}^{2}}\left[\begin{array}{cc}
V_{\alpha} & V_{\beta} \\
V_{\beta} & -V_{\alpha}
\end{array}\right]\left[\begin{array}{c}
-\bar{p} \\
-\bar{q}
\end{array}\right]
$$

The final compensating currents components in a, b, c reference frame in terms of $\alpha \beta$ given as 


$$
\left[\begin{array}{l}
i_{C a}^{*} \\
i_{C b}^{*} \\
i_{C c}^{*}
\end{array}\right]=\sqrt{\frac{2}{3}}\left[\begin{array}{ccc}
1 & -\frac{1}{2} & -\frac{1}{2} \\
0 & \frac{\sqrt{3}}{2} & -\frac{\sqrt{3}}{2}
\end{array}\right]\left[\begin{array}{l}
i_{C \alpha}^{*} \\
i_{C \beta}^{*}
\end{array}\right]
$$

These are the compensation current injected by the shunt active filter to reduce harmonics in three phase-three wire systems.

\section{SIMULATION RESULTS}

\subsection{THREE PHASE SYSTEM FEEDING A NON- LINEAR LOAD}

The Below figure shows the line model of Three phase THREE WIRE system feeding Non-Linear load

\subsection{1without shunt active power filter}

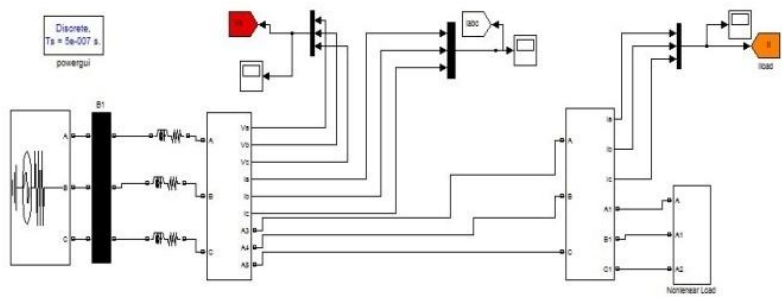

\section{NONLINEAR LOAD MODEL}

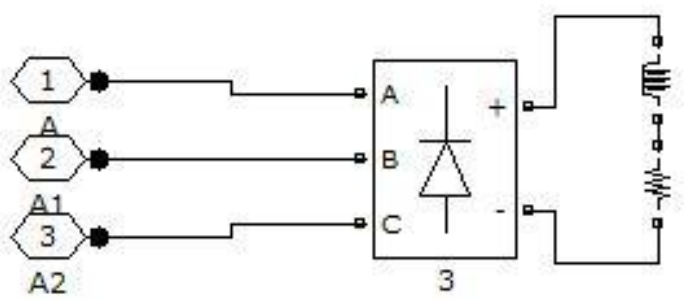

Fig.4.2 Three Phase balanced Non-linear Load model

\subsubsection{OUTPUT WAVE FORMS WITHOUT SHUNT ACTIVE FILTER FOR THREE PHASE} BALANCED LOAD

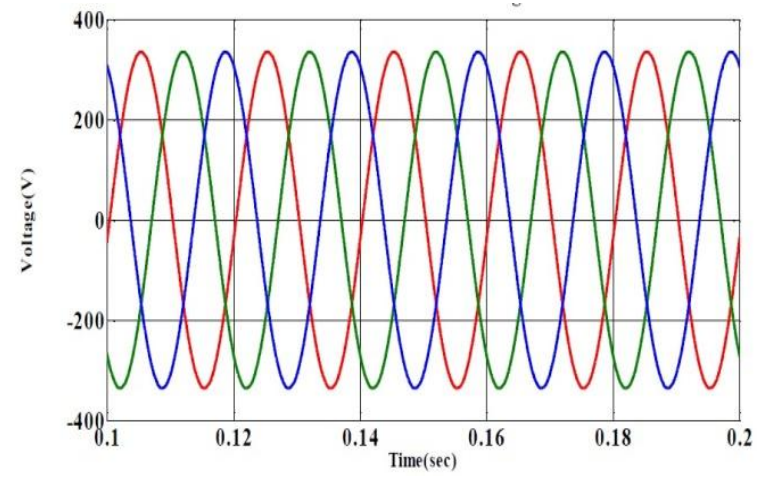

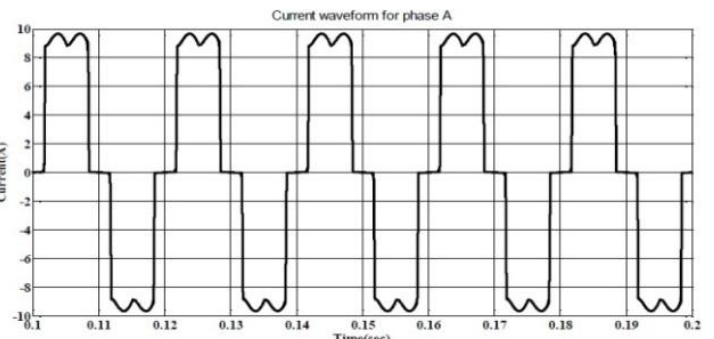

(b)

Fig.4.1.2 Waveform of (a) Three Phase voltage

(b) Line Current without shunt active filter for phase A

When the nonlinear load consists of an uncontrolled threephase rectifier with an inductance of $30 \mathrm{mH}$ and a $60 \Omega$ resistor connected in series on the dc side shows in "Fig.6.1". The line and load current wave forms as shown above. The magnitude of the distorted line current for phase -A is 10.26A and Total Harmonic Distortion of the Phase load current is $29.53 \%$

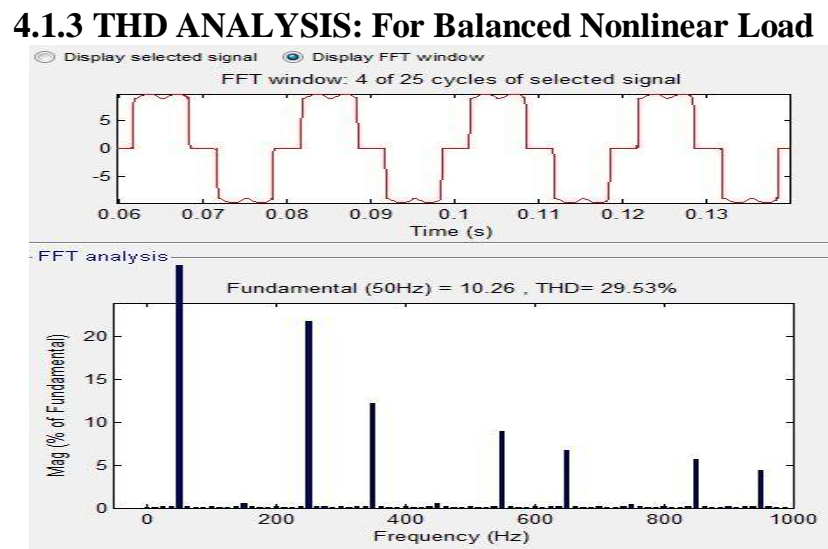

Fig.4.1.3 FFT Analysis for Phase-A Line Current without APF

\subsection{With a shunt active filter}

Three Phase-Three wire System a Non-Linear Load with Shunt Active Power Filter

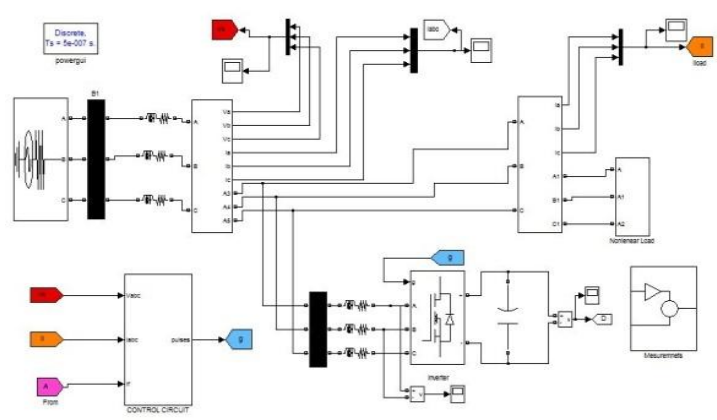

Fig.4.2.1 Three Phase System Feeding a Non-linear Load with Shunt Active Power Filter

The power circuit is a three-phase system supplied by a sinusoidal balanced three-phase $415 \mathrm{~V}$ source with a source inductance of $1 \mathrm{mH}$ and a source resistance of $0.1 \Omega$. The inverter consists of an Insulated Gate Bipolar Transistor 
(IGBT) bridge. On the dc side, $1500 \mu \mathrm{F}$ capacitor is connected

\section{OUTPUT WAVE FORMS}

\section{With shunt active filter}

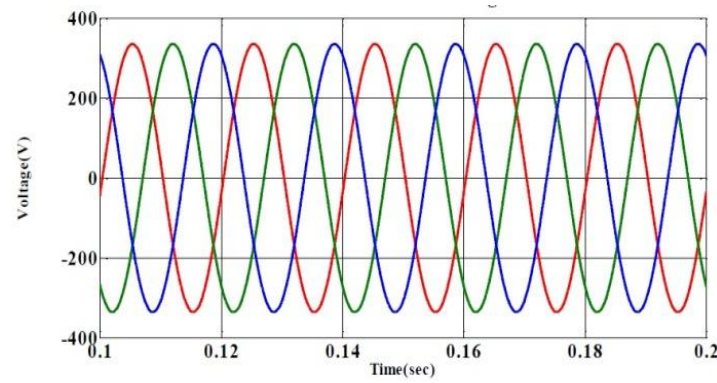

a.
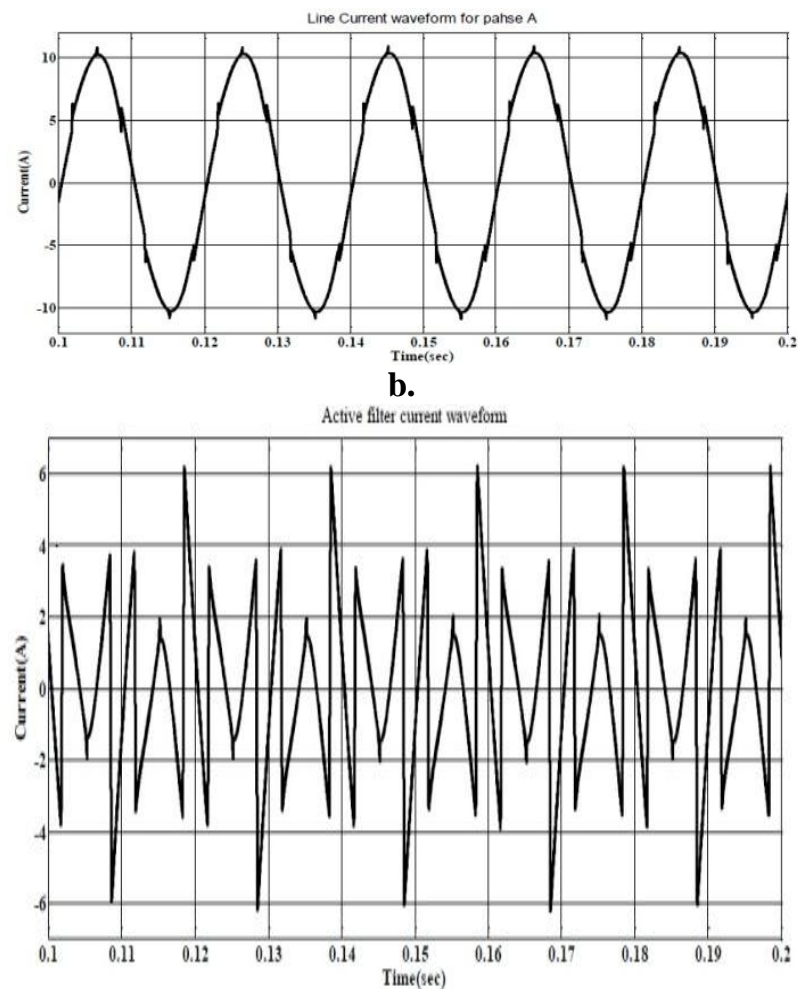

c.

Waveforms of

(a) Three Phase Line Voltage

(b) Line Current for phase A

(c) Harmonic current with shunt active filter for phase A

FFT ANALYSIS: For Phase-A Line Current with shunt active filter

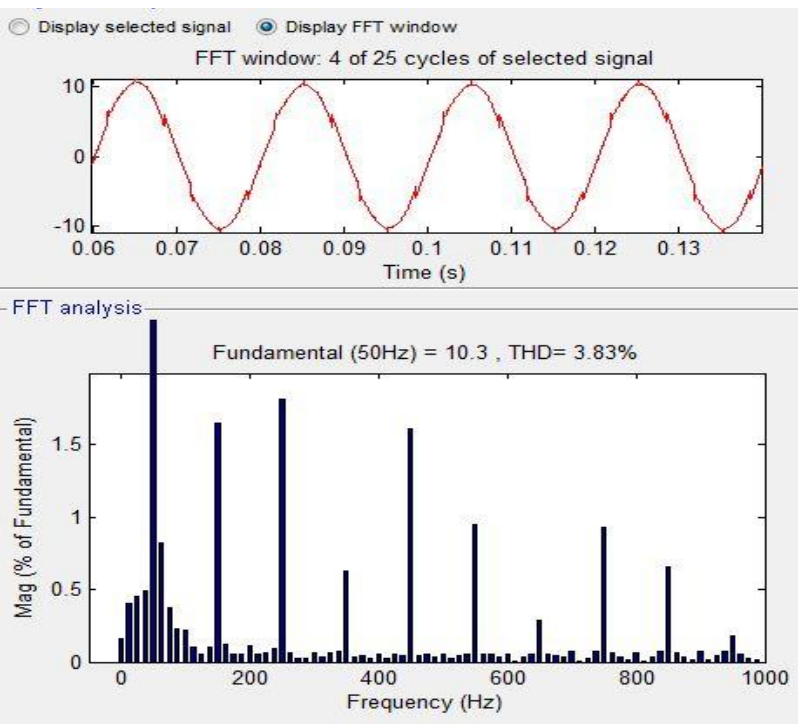

FFT Analysis for Phase-A Line Current with shunt active filter

When we connect a nonlinear balanced load to the system the line and load current wave forms after compensation i.e after connecting shunt active filter as shown above. The magnitude of the line current for phase $-\mathrm{A}$ is $10.3 \mathrm{~A}$ and Total Harmonic Distortion of the Phase line current is $3.83 \%$.

\subsection{OUTPUT WAVE FORMS WITH AND WITHOUT SHUNT ACTIVE FILTER FOR}

\section{THREE PHASE UNBALANCED LOAD}

In this case, the three-phase load is built with three single phase uncontrolled rectifiers with inductors and resistors connected in series at the dc side with the values of $a, b$ and c phase are "80,3mH" and " $70 \Omega, 300 \mathrm{mH}^{\prime}$ " and " $30 \Omega, 30 \mathrm{mH}$ ".

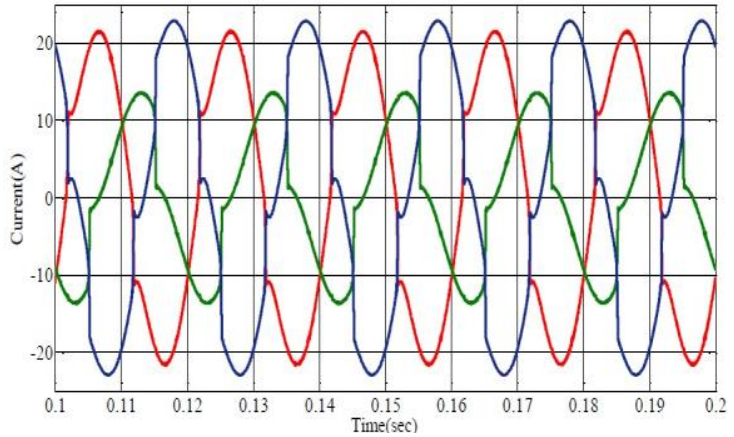

5.1.1. Wave forms of Three Phase Line Current without shunt active filter 


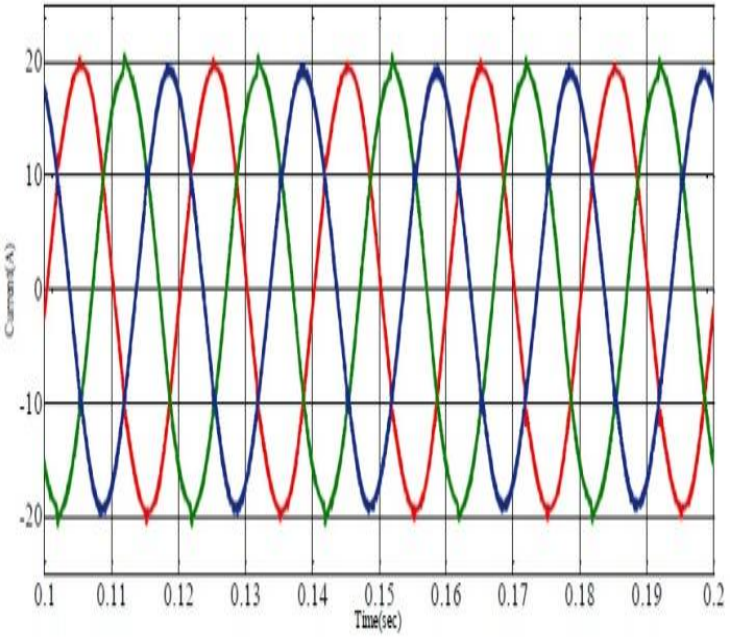

5.1.2 a.

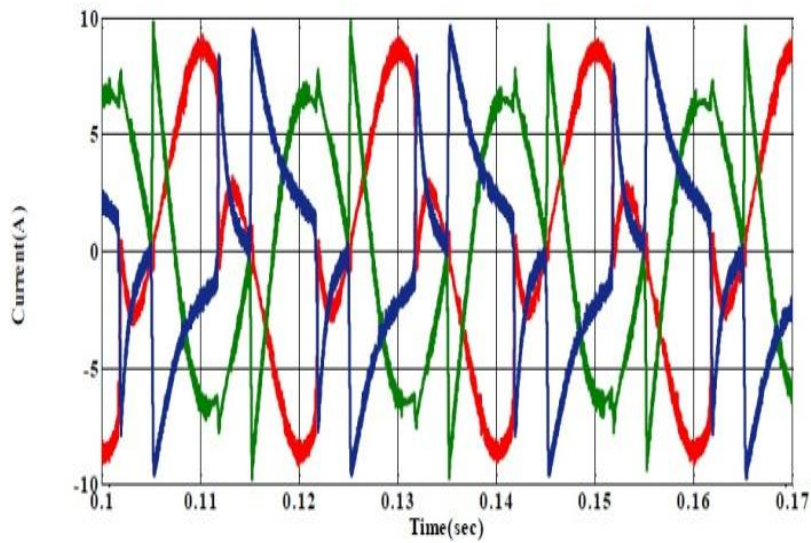

5.1.2 b.

\subsubsection{Waveforms are}

(a) Three Phase Line Current with shunt active filter

(b) Harmonic current with shunt active Filter

\section{THD ANALYSIS:}

For Unbalanced Nonlinear Load without active filter

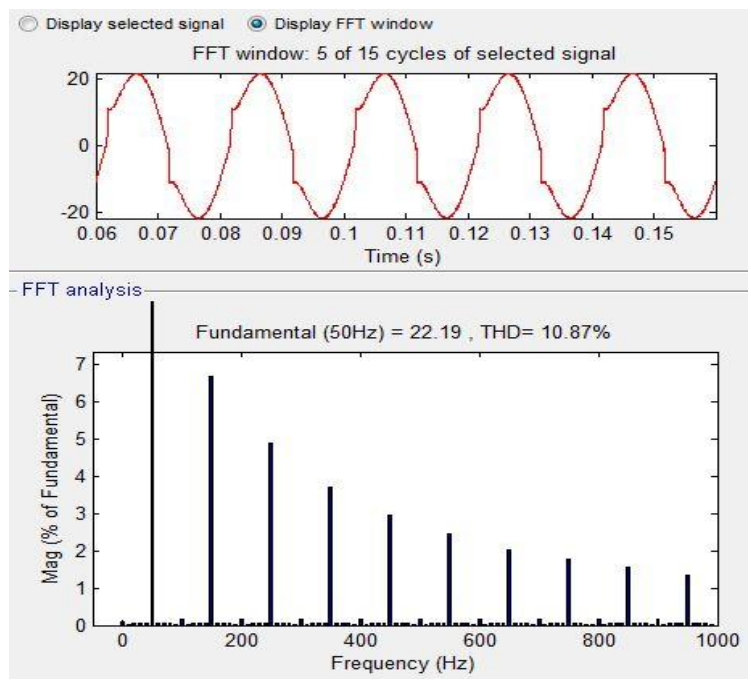

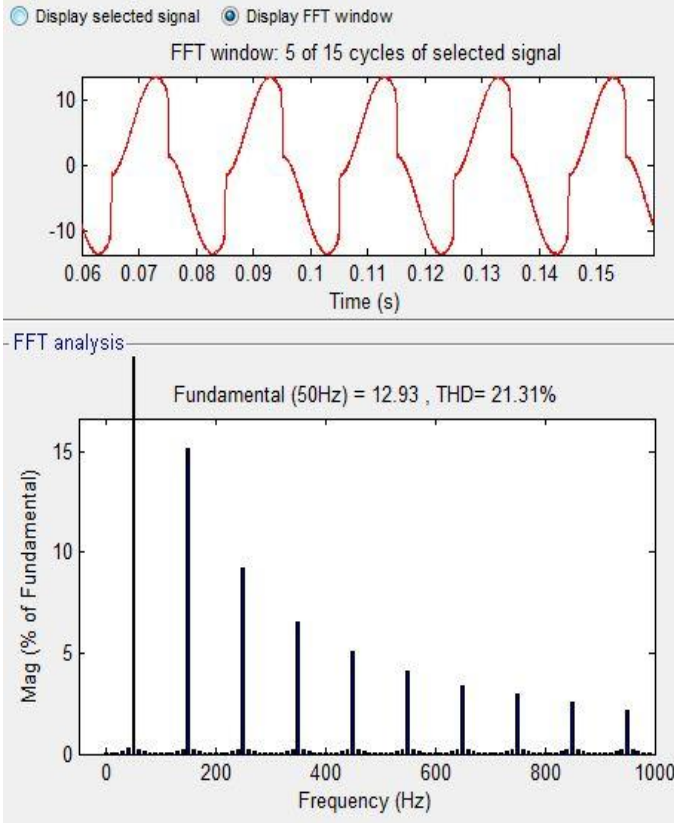

Fig.5.1.2 FFT Analysis for (a) Phase-A Line Current (b) for Phase-B Line Current

THD ANALYSIS: For Unbalanced Nonlinear Load with active filter

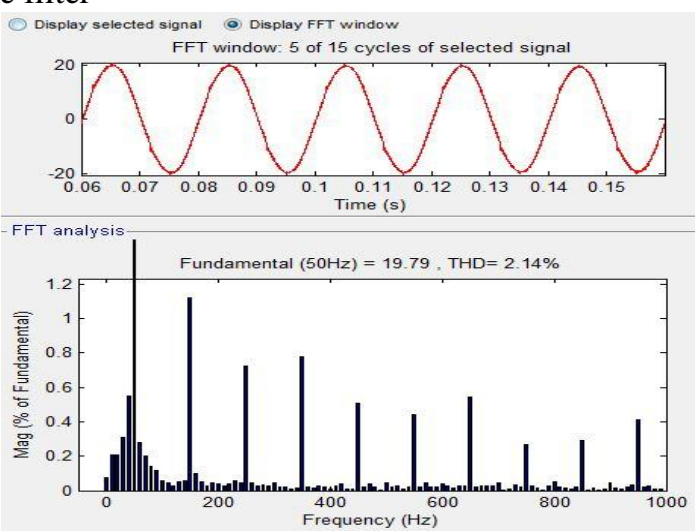

a.
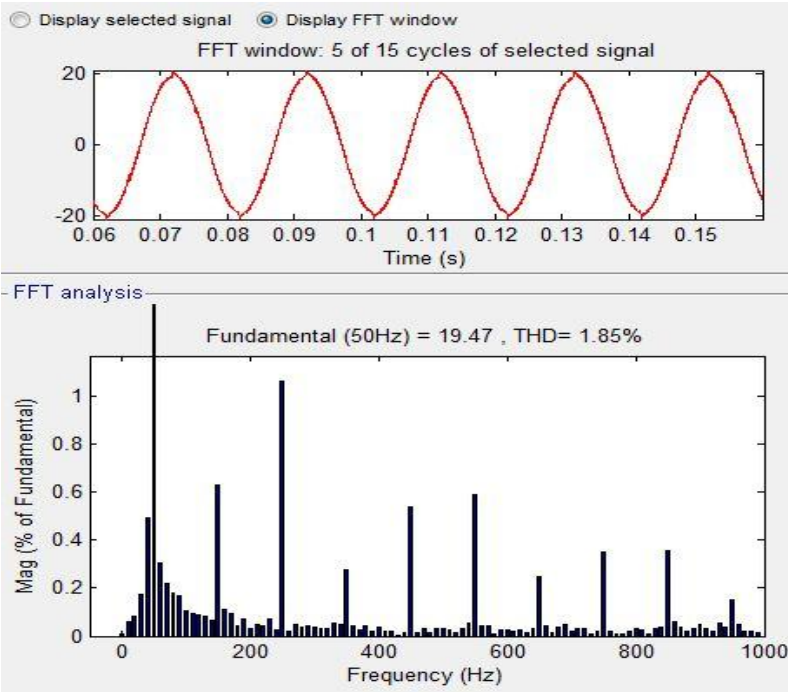

b.

FFT Analysis for (a) Phase-A Line Current (b) for Phase-B Line Current 
When we connect a nonlinear unbalanced load to the system, before compensation i.e without active filter the line and load current magnitudes of the phase A, phase B, phase $\mathrm{C}$ are 22.19A,12,93A,23.2A and Total Harmonic Distortion of line currents of Phases A,B,C are $10.87 \%, 21.31 \%, 13.87 \%$

After compensation i.e with shunt active filter the line current magnitudes of the phase $\mathrm{A}$, phase $\mathrm{B}$, phase $\mathrm{C}$ are19.79A, 19.47A,19.01A and Total Harmonic Distortion of line currents of Phases A,B,C are2.14\%,1.85\%,1.85\%.

\section{CONCLUSION}

Power quality management is the main problem that the industry is facing today. This is mainly affected by the generation of harmonics. The growing use of electronic equipment produces a large amount of harmonics in distribution systems because of non-sinusoidal currents consumed by non-linear loads. The system of Shunt Active Power Filter is proposed in this work.

Conventional way of harmonics elimination by using passive filter might suffer from parasitic problem. It has been shown that three phase active filter based on $\mathrm{p}-\mathrm{q}$ theory can be implemented for harmonic mitigation and power factor correction. Harmonics mitigation carried out by the active filter was showed In this project and we clearly calculate the Total Harmonic distribution(THD) with active filters and without active filters.

\section{REFERENCES}

[1] W. M. Grady, M. J. Samotyj, and A. H. Noyola, "Survey of active power line conditioning methodologies," IEEE Transactions on Power Delivery, vol. 5, no. 3, Jul. 1990, pp. 1536-1542.

[2] F. Z. Peng and D. J. Adams, "Harmonics sources and filtering approaches"in Proc. Industry Applications Conf., Oct. 1999, vol. 1, pp.448-455

[3] S. Jain, P. Agarwal, and H. O. Gupta, "Design simulation and experimental investigations on a shunt active power filter for harmonics and reactive power compensation," Electrical Power Components and Systems, vol. 32, no. 7, Jul. 2003, pp. 671-692.

[4] F. Z. Peng, H. Akagi, and A. Nabae, "Study of active power filters using quad series voltage source PWM converters for harmonic compensation," IEEE Transactions on Power Electronics, vol. 5, no. 1, Jan. 1990, pp. 9-15

[5] H. Akagi, Y. Kanzawa, and A. Nabae (1984) Instantaneous reactive power compensators comprising switching devices without energy components. IEEE Trans. Ind. Appl., 20 (3), pp. 625-630

[6] M. Depenbrock, V. Staudt, H. Wrede, "Concerning instantaneous power compensation in three-phase systems by using $\mathrm{p}-\mathrm{q}-\mathrm{r}$ theory," IEEE Transactions on Power Electronics, vol. 19, no. 4, pp. 1151-1152, Jul. 2004

[7] L.A.Morgan, J.W.Dixon\&R.R.Wallace, "A three phase active power filter operating with fixed switching frequency for reactive power and current harmonics compensation," IEEE Transactions on Industrial Electronics, vol.42, no.4, August 1995, pp 402-408.

[8] B. Singh, A. Chandra, and K. Al-Haddad, "Computer-aided modeling and simulation of active power filters," Electrical Machines and Power Systems, vol. 27, 1999, pp. 1227-1241.

[9] H.Akagi, Edson Hirokazu Watanabe, and Mauricio Aredes Instantaneous Power Theory and Applications to Power Conditioning" Wiley IEEE Press, Hoboken,New Jersey (IEEE Press Series on Power Engineering), 2007 Mark McGranaghan "Active Filter Design and Specification for Control of Harmonics in Industrial and Commercial Facilities", Electrotek Concepts, Inc. 2002.

[10] J.W.Dixon, J.J.Garcia\&L.Morgan, "Control system for three phase active power filter which simultaneously compensates power factor and unbalanced loads," IEEE Transactions on Industrial Electronics, vol.42, no.6, 1995, pp636-641.

[11] E.H.Watanbe, R.M.Stephan\&M.Aredes, "New concepts of instantaneous active and reactive powers in electrical systems with generic loads," IEEE Transactions on Power Delivery, vol.8, no.2, April 1993, pp.697-703.

12] L. S. Czarnecki, "Instantaneous reactive power $\mathrm{p}-\mathrm{q}$ theory and power properties of three-phase systems," IEEE Transactions onPower Delivery, vol. 21, no. 1, pp. 362-367, January 2006

[13] H. Akagi, S. Ogasawara, and H. Kim "The theory of instantaneous power in three-phase four-wire systems: a comprehensive approach", Conf. Rec. of IEEE IAC, Vol. 1, 1999, pp. 431-439.

14] L. Rossetto, and P. Tenti, "Evaluation of Instantaneous Power Terms in Multi-Phase Systems: Techniques and Application to Power-Conditioning Equipment," ETEP, vol. 4, No. 6, Nov./Dec. 1994, pp. 469-475

[15] M. Aredes, H. Akagi, E. H. Watanabe, E. V. Salgado, L. F. Encarnação, "Comparisons Between the p-q and p-q-rTheories in Three- Phase Four- Wire Systems," IEEE Transactionson Power Electronics, , vol. 24, no. 4,924-933, April 2009.

16] V.Soares, P.Verdelho\& G.D. Marques, "An instantaneous active and reactive current component method of active filter," IEEE Transactions on Power Electronics, vol.15, no.4, July 2000, pp.660-669.

[17] J.C. Montano and P. Salmeron "Strategies of instantaneous compensation for three-phase four-wire circuits", IEEE Trans. Power Delivery, in press, preprint order number: PE-140PRD (03-2002).

[18] H. Akagi, S. Ogasawara, and H. Kim "The theory of instantaneous power in three-phase four-wire systems: a comprehensive approach", Conf. Rec. of IEEE IAC, Vol. 1, 1999, pp. 431-439 